\title{
Correction to: Artemisinin derivatives inactivate cancer-associated fibroblasts through suppressing TGF- $\beta$ signaling in breast cancer
}

Yuyuan Yao ${ }^{1+}$, Qinglong Guo ${ }^{1 \dagger}$, Yue Cao ${ }^{1}$, Yangmin Qiu', Renxiang Tan'², Zhou Yu' ${ }^{1}$ Yuxin Zhou ${ }^{1}$ and Na Lu ${ }^{1 *}$

Correction to: J Exp Clin Cancer Res (2018) 37: 282 https://doi.org/10.1186/s13046-018-0960-7

In the original publication of this article [1], Fig. 3 is wrong, but does not affect discussions and conclusions drawn in the article.

The corrected Fig. 3 is shown below:

\section{Author details}

'State Key Laboratory of Natural Medicines, Jiangsu Key Laboratory of Carcinogenesis and Intervention, School of Basic Medicine and Clinical Pharmacy, China Pharmaceutical University, 24 Tongjiaxiang, Nanjing 210009, People's Republic of China. ${ }^{2}$ State Key Laboratory Cultivation Base for TCM Quality and Efficacy, Nanjing University of Chinese Medicine, 138 Xinlin Road, Nanjing 210023, People's Republic of China.

Published online: 05 November 2019

\section{Reference}

1. Yao Y, et al. Artemisinin derivatives inactivate cancer-associated fibroblasts through suppressing TGF- $\beta$ signaling in breast cancer. J Exp Clin Cancer Res. 2018;37:282. https://doi.org/10.1186/s13046-018-0960-7.

\footnotetext{
* Correspondence: nalu@cpu.edu.cn

†Yuyuan Yao and Qinglong Guo contributed equally to this work.

'State Key Laboratory of Natural Medicines, Jiangsu Key Laboratory of

Carcinogenesis and Intervention, School of Basic Medicine and Clinical

Pharmacy, China Pharmaceutical University, 24 Tongjiaxiang, Nanjing 210009,

People's Republic of China

Full list of author information is available at the end of the article
}

(c) The Author(s). 2019 Open Access This article is distributed under the terms of the Creative Commons Attribution 4.0 International License (http://creativecommons.org/licenses/by/4.0/), which permits unrestricted use, distribution, and reproduction in any medium, provided you give appropriate credit to the original author(s) and the source, provide a link to the Creative Commons license, and indicate if changes were made. The Creative Commons Public Domain Dedication waiver (http://creativecommons.org/publicdomain/zero/1.0/) applies to the data made available in this article, unless otherwise stated. 


$$
\text { A }
$$

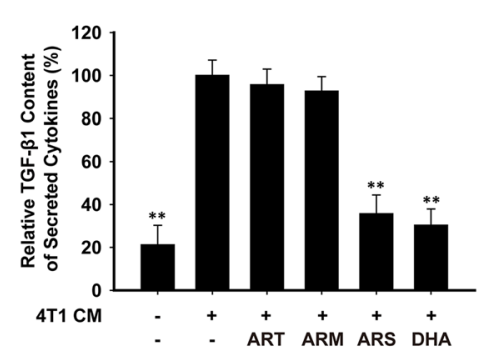

B
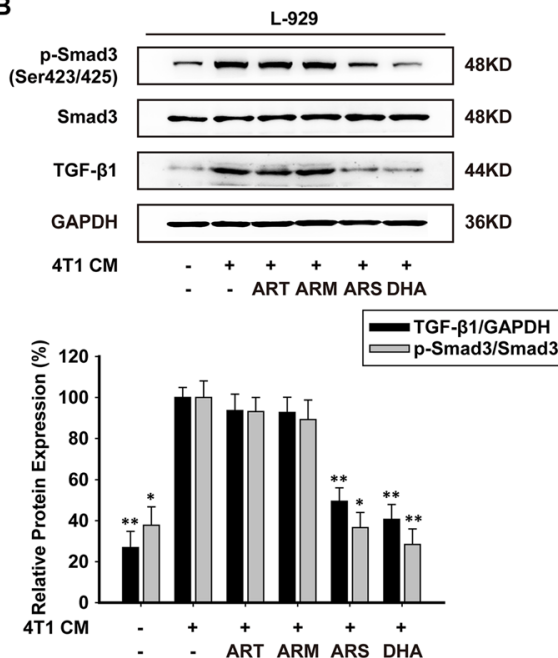

C

Migration
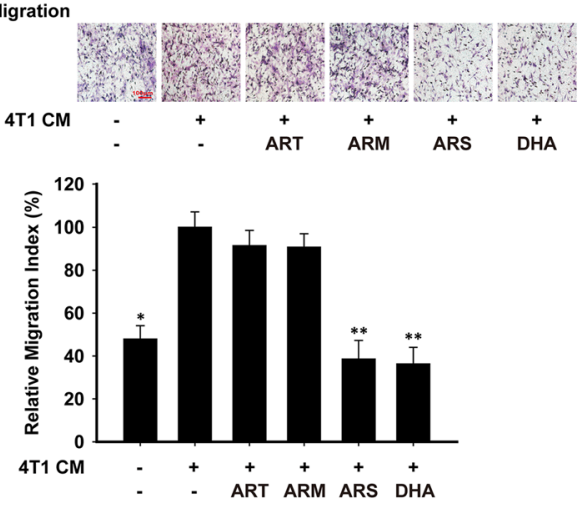

Invasion

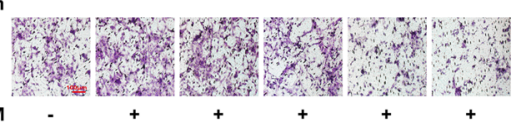

$\begin{array}{ccccccc} & & & & & & \\ \mathrm{T} 1 \mathrm{CM} & - & + & + & + & + & + \\ & - & - & \text { ART } & \text { ARM } & \text { ARS } & \text { DHA }\end{array}$

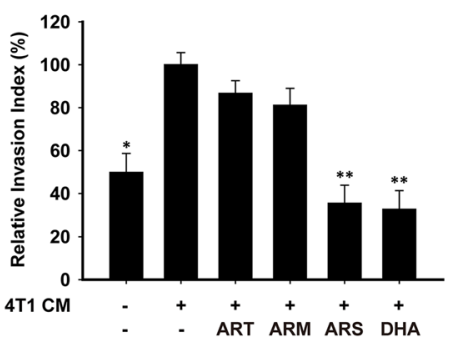

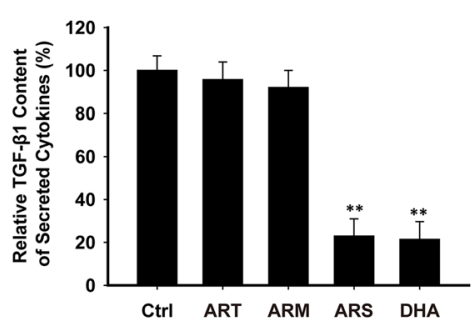
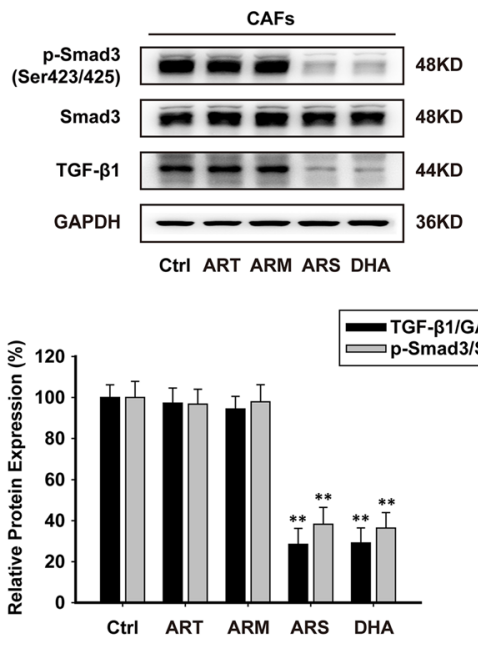

Migration
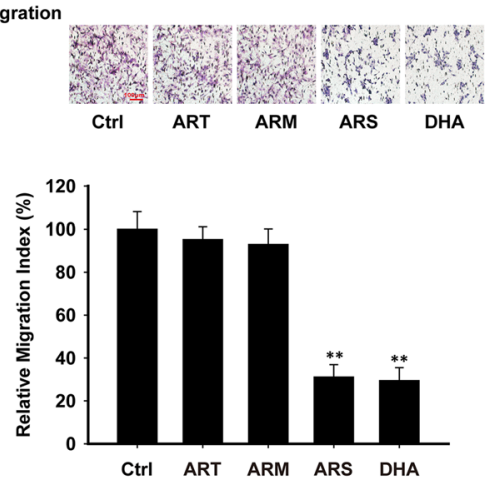

Invasion
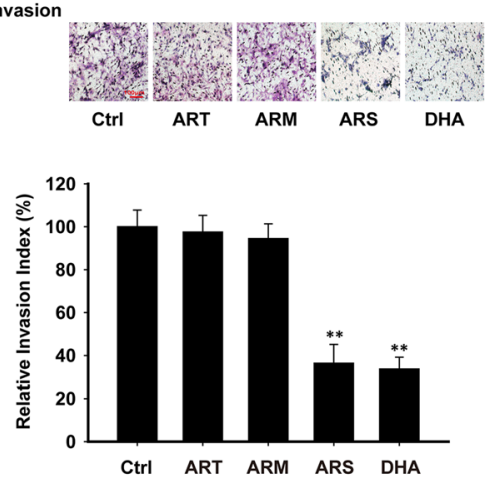

Fig. 3 